\title{
Optimization and Quality Analysis of Different Extraction Methods of Palm Seed Oil
}

\author{
Qi-Zhao Li ${ }^{1}$ and Zheng-Qun Cai ${ }^{2}{ }^{2}$ \\ ${ }^{1}$ School of Pharmacy, Anhui Xinhua University, Hefei 230088, China \\ ${ }^{2}$ School of Foreign Studies, Anhui Jianzhu University, Hefei 230601, China \\ Correspondence should be addressed to Zheng-Qun Cai; caizhengqun1983@163.com
}

Received 25 March 2021; Accepted 22 April 2021; Published 3 May 2021

Academic Editor: Huihua Chen

Copyright ( 2021 Qi-Zhao Li and Zheng-Qun Cai. This is an open access article distributed under the Creative Commons Attribution License, which permits unrestricted use, distribution, and reproduction in any medium, provided the original work is properly cited.

The extraction process of palm seed oil was optimized. Using palm seed as raw material, oil extraction rate was used as an index. The effects of flash extraction, ultrasonic-assisted extraction, supercritical extraction, and aqueous enzymatic extraction on the yield of palm seed oil were investigated. The extraction methods and technological conditions of palm seed oil were optimized by the orthogonal method on the basis of single factor. The seed oil was analyzed and detected. The results showed that the water enzymatic extraction method was the best, and the optimal extraction conditions were as follows: enzymatic hydrolysis time $16 \mathrm{~h}$, enzymatic hydrolysis temperature $50^{\circ} \mathrm{C}$, and enzymatic content $2.0 \%$. The oil yield of palm seed was $16.48 \%$. Conclusion. Water enzymatic extraction process of palm seed oil is reasonable, the active ingredients are rich, and the quality of seed oil is better, providing reference for the development and research of palm seed oil.

\section{Introduction}

Palm seeds are the dried fruits of palm trees. Palms are widely planted and their mature fruits are used to dry them. The seeds are rich in active ingredients such as ursolic acid, mannitol, oleanolic acid, quercetin, oleuropein, $\beta$-sitosterol, betulin, and rhamnose. The active ingredients mainly have hemostasis, strengthen essence, nourish the liver and kidney, strengthen the body, treat blood collapse and gastroenteritis, treat eye diseases, increase the number of peripheral white blood cells, lower blood sugar, protect the liver, affect the phagocytosis of the body's reticuloendothelial system function, can improve immune function, can obviously inhibit a variety of allergic reactions, reduce body serum total cholesterol and lipid peroxide, etc. Increasing the anti-inflammatory mediator histamine causes capillary permeability and reduces the incidence of atherosclerosis. Palm seeds contain about 18 percent fat. At present, the palm is mostly used for landscaping except a few for medicinal purposes. The economic value of the palm seed is not fully utilized, and there are few reports on the extraction and separation of its seed oil. Therefore, different extraction methods, such as flash extraction, ultra-rapid extraction, ultrasonic extraction, and water enzyme extraction, were used to extract palm seed oil in this experiment in order to obtain the best extraction method and technological conditions of palm seed oil. The oil yield of different varieties was compared, and the best varieties were selected to provide reference for the comprehensive utilization and development of palm seeds.

\section{Materials and Methods}

2.1. Materials and Reagents. Four varieties of dry peeled palm seed fruit were purchased. Palm seeds were purchased from the Bozhou medicinal material market in Anhui Province and were identified by Professor Wei Qiang of Anhui Xinhua University. The protease, amylase, bromelain, papain, and other reagents needed for the experiment were purchased from China Reagent Company. Papain was purchased from Sinopharm Group. $\mathrm{KOH}, \mathrm{NaOH}$, petroleum ether, and so on were all analytically pure and purchased from Tianjin Best.

2.2. Experimental Instruments and Equipment. Supercritical extractor HA120-50-01, flash extractor JHBE-20A, gas chromatograph 7890B, Thermo Fe-260, UV-visible spectrophotometer, rotary evaporator RE-2000B, electronic 
balance AUW220, constant-temperature incubator LP/ DHS-225, and multifunction grinder JP-800C were used.

\section{Experimental Methods}

3.1. Oil Flash Extraction of Palm Seed. Weigh $100 \mathrm{~g}$ of dried and crushed palm seed powder; add petroleum ether according to a certain ratio of solid to liquid; set flash voltage, extraction time, extraction temperature, and flash extraction; remove impurities and filter; collect the extract; decompress-rotary steam to recover the solvent; dry, weigh, and calculate the extraction rate of oil [1].

3.2. Supercritical Extraction of Palm Seed Oil. $100 \mathrm{~g}$ of palm seed powder was accurately weighed into the extraction kettle; the extraction temperature, extraction time, and extraction pressure were set for supercritical extraction; $\mathrm{CO}_{2}$ fluid was separated, dried, and weighed; and the yield of palm seed oil was calculated [2].

3.3. Ultrasound-Assisted Extraction of Palm Seed Oil. Accurate weighing of $100 \mathrm{~g}$ of palm seed powder over 40 mesh into conical flask, adding appropriate amount of petroleum ether, and setting ultrasonic power, temperature, and time for ultrasonic extraction for 3-5 times are carried out. The filtrate was combined, the solvent was recovered by decompression, and the extraction rate of palm seed oil was calculated by drying and weighing [3].

3.4. Enzymatic Extraction of Palm Seed Oil. The palm seeds were accurately weighed and $100 \mathrm{~g}$ of 40 mesh powder was put into a beaker, and an appropriate amount of distilled water was added. The amount of enzyme, enzymatic hydrolysis time, and enzymatic hydrolysis temperature were set to be extracted by water enzymatic method. Enzyme elimination, extraction centrifugation, decompression recovery, drying, and weighing were performed to calculate the extraction rate of palm seed oil [4].

\subsection{Design of Extraction Conditions for Palm Seed Oil}

3.5.1. Single-Factor Design of Palm Seed Oil Extraction Method. Extraction conditions for examining flash style material liquid ratio, extraction time, extraction voltage influence on palm seeds oil extraction rate, respectively, will flash type extraction single factor set to liquid ratio $(1: 10,1$ : $20,1: 30,1: 40$, and $1: 50)$, extraction time $(30,60,90,120$, and $150 \mathrm{~s})$, extracting voltage $(75,100,125,150$, and $175 \mathrm{v})$, experiment of five levels, in a certain single factor when the other two factors maintain the best level. Fixed factor levels were set as the solid-liquid ratio of $1: 30$, extraction voltage of $150 \mathrm{~V}$, and extraction time of $120 \mathrm{~S}$ [5].

3.5.2. Single-Factor Design of Ultrasonic-Assisted Extraction of Palm Seed Oil. For inspection, ultrasonic temperature, ultrasonic time, and solid-liquid ratio on the palm seeds oil extraction and ultrasonic extraction, respectively, single factor is set to the material liquid ratio $(1: 10,1: 20,1: 30$, and $1: 40)$, ultrasonic time $(20,30,40,50$, and $60 \mathrm{~min})$, ultrasonic temperature $(40,45,50,55$, and 60$)$, experiment of five levels, in a certain single factor when the other two factors maintain the best level. Fixed factor levels were set as solid-liquid ratio of $1: 30$, ultrasonic power $450 \mathrm{~W}$, ultrasonic temperature of 55, and extraction time of $50 \mathrm{~min}$ [6].

3.5.3. Single-Factor Design for Supercritical Extraction of Palm Seed Oil. To study extraction temperature, extraction pressure, and extraction time on the yield of palm seed oils, respectively, extraction temperature $(30,40,50,60$, and 70$)$, extraction time $(60,70,80,90$, and $100 \mathrm{~min})$, extraction pressure $(10,15,20,25$, and $30 \mathrm{MPa})$, experiment of five levels, in a certain single factor when the other two factors maintain the best level. Fixed factor levels were set as extraction temperature 50 , extraction pressure $20 \mathrm{MPa}$, and extraction time $60 \mathrm{~min}$ [7].

3.5.4. Single-Factor Design for Oil and Water Enzymatic Extraction of Palm Seed. For inspection with enzyme, enzyme solution temperature, solution time on the yield of palm seed oils, respectively, with enzyme amount $(0.50,1.00$, $1.50,2.00$, and $2.50 \%)$, enzymolysis time $(8,12,16,20$, and 24), temperature, and enzyme solution ( $35,40,45,50$, and 55), experiment of five levels, in a certain single factor when the other two factors maintain the best level. The fixed factor levels were set as $1.00 \%$ enzymatic dosage, 50 enzymatic hydrolysis temperature, and $16 \mathrm{~h}$ enzymatic hydrolysis time [8].

3.5.5. Design Orthogonal Test. On the basis of the above single-factor experiments, orthogonal experiments were used to optimize the extraction conditions of palm seed oil with the extraction rate of palm seed oil as the index. [9].

3.6. Oil Composition Analysis of Palm Seeds. The palm seed oil sample was accurately transferred into a $1.0 \mathrm{~mL}$ flask, and $5 \% \mathrm{KOH}$-methanol solution was added in $2.0 \mathrm{ml} 40^{\circ} \mathrm{C}$ water bath for $15 \mathrm{~min}$. Then, the sample was cooled at room temperature and dissolved in $2.0 \mathrm{ml} n$-hexane and moved to a $10 \mathrm{~mL}$ volumetric flask for constant volume. After standing for $1 \mathrm{~d}$, the organic phase was absorbed and filtered with a 0.45 um filter membrane for standby detection [10].

\section{Results and Discussion}

\subsection{Single-Factor Experiment on Extraction Rate of Palm Seed Oil}

4.1.1. Investigation of Single-Factor Experiment of Flash Extraction of Palm Seed Oil (See Figure 1). Figure 1 shows that the solid-liquid ratio, extraction voltage, and extraction time have significant effects on the oil yield of palm seed. As palm seeds and solid-liquid ratio, flash extraction voltage, extraction time increase, the oil extraction rate rises gradually, in the ratio of material liquid: $1: 30$, extracting time 

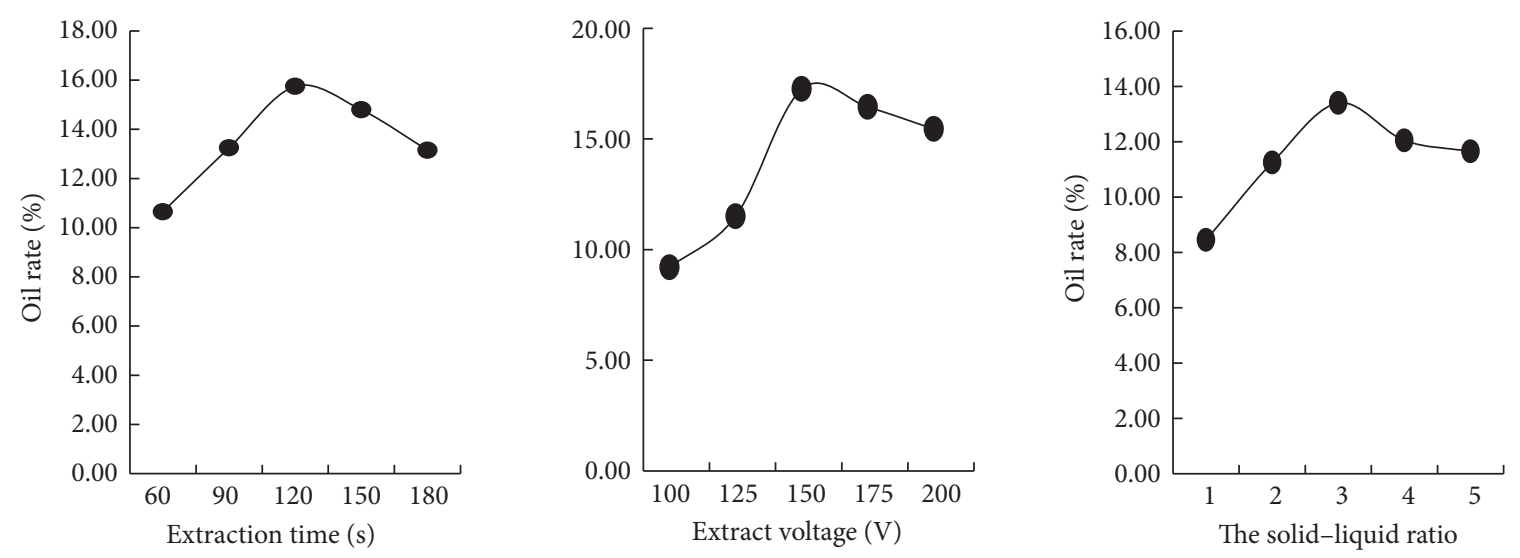

FIgURE 1: Influence of different factors on extraction rate of palm seed oil by the flash extraction method.

$120 \mathrm{~s}$, extraction voltage $150 \mathrm{v}$ to extract the oil yield declined slightly after $120 \mathrm{~s}$, considering flash type palm seed oil extraction experiments choice for the extraction of material liquid than $1: 30$, extraction time $120 \mathrm{~s}$, voltage $150 \mathrm{v}$, experiment in next step [11].

4.1.2. Single-Factor Study of Ultrasound-Assisted Extraction of Palm Seed Oil (See Figure 2). It can be seen from Figure 2 that ultrasonic time, ultrasonic temperature, and solid-liquid ratio had significant effects on the oil yield of palm seed. With the increase of ultrasonic time [12], solid-liquid ratio, and ultrasonic temperature, the oil yield of palm seed increased significantly. However, after the solid-liquid ratio of $1: 25$, ultrasonic temperature of $50^{\circ} \mathrm{C}$, and ultrasonic time of $50 \mathrm{~min}$, the extraction yield of oil was slightly decreased. Considering the overall solid-liquid ratio of $1: 30$, ultrasonic time of $40 \mathrm{~min}$, ultrasonic power/W, and ultrasonic temperature of 55, the ultrasonic assisted extraction experiment of palm seed oil was selected as the basis for the later experiment [13].

4.1.3. Single-Factor Study of Supercritical Extraction Experiment of Palm Seed Oil (See Figure 3). It can be seen from Figure 3 that extraction temperature, extraction pressure, and extraction time have significant effects on the oil yield of palm seed. With the increase of extraction temperature, extraction pressure, and extraction time, the oil yield of palm seed increases significantly. However, the oil yield decreased slightly after extraction temperature $50^{\circ} \mathrm{C}$, extraction time $90 \mathrm{~min}$, and extraction pressure $20 \mathrm{MPa}$. Considering the supercritical extraction experiment of palm seed oil, the extraction temperature $50^{\circ} \mathrm{C}$, extraction time $90 \mathrm{~min}$, and extraction pressure $20 \mathrm{MPa}$ were selected as the basis of the later experiment [14].

4.1.4. Single-Factor Study of Oil-Water Enzymatic Extraction of Palm Seed (See Figure 4). It can be seen from Figure 4 that the amount of enzyme added, the temperature of enzymatic hydrolysis and the time of enzymatic hydrolysis have significant effects on the yield of palm seed oil. With the increase of the amount of compound enzyme added, the temperature of enzymatic hydrolysis, and the time of enzymatic hydrolysis, the yield of palm seed oil increases significantly. However, the yield of oil was slightly decreased after the addition of $1.0 \%$ enzyme amount, $16 \mathrm{~h}$ enzymatic hydrolysis time, and $50^{\circ} \mathrm{C}$ enzymatic hydrolysis temperature. Considering the overall selection of palm seed oil-water enzymatic extraction experiment, $0.20 \%$ enzyme amount, $50^{\circ} \mathrm{C}$ enzymatic hydrolysis temperature, and $20 \mathrm{~h}$ enzymatic hydrolysis time were selected as the basis of the later experiment [15].

\subsection{Orthogonal Experiment on Extraction of Palm Seed Oil}

4.2.1. Orthogonal Experiment of Oil Scintillation Extraction of Palm Seed. For the orthogonal experiment of flash extraction of palm seed oil, the factor levels are shown in Table 1, and the orthogonal experiment is shown in Table 2.

It can be seen from Table 2 that in the flash extraction experiment of palm seed oil, extraction time, extraction voltage, and solid-liquid ratio all had influences on the oil yield obtained from the extraction. Because $\mathrm{B}>\mathrm{C}>\mathrm{A}$, it can be seen that the extraction time is greater than the extraction voltage is greater, and the influence is greater than the solidliquid ratio. The extraction voltage had the greatest influence, and the optimal extraction conditions were as follows: $\mathrm{A}_{3} \mathrm{~B}_{3} \mathrm{C}_{3}$, extraction time of $120 \mathrm{~S}$, namely, extraction voltage of $150 \mathrm{~V}$, solid-liquid ratio of $1: 30$ [16].

4.2.2. Orthogonal Experiment of Ultrasonic-Assisted Extraction of Palm Seed Oil. The orthogonal experiment of ultrasound-assisted extraction of palm seed oil and the factor levels are shown in Table 3 and the orthogonal experiment in Table 4.

As can be seen from Table 4, ultrasonic time, ultrasonic power, and temperature ultrasonic all had influences on the extraction yield of palm seed oil in the ultrasound-assisted extraction experiment, because $\mathrm{C}>\mathrm{B}>\mathrm{A}$ showed that the influence of ultrasonic power on the extraction yield of palm seed oil was greater than that of ultrasonic time and temperature. Ultrasonic power had the greatest effect, and the optimal extraction conditions were as follows: $\mathrm{A}_{2} \mathrm{~B}_{2} \mathrm{C}_{2}$, 

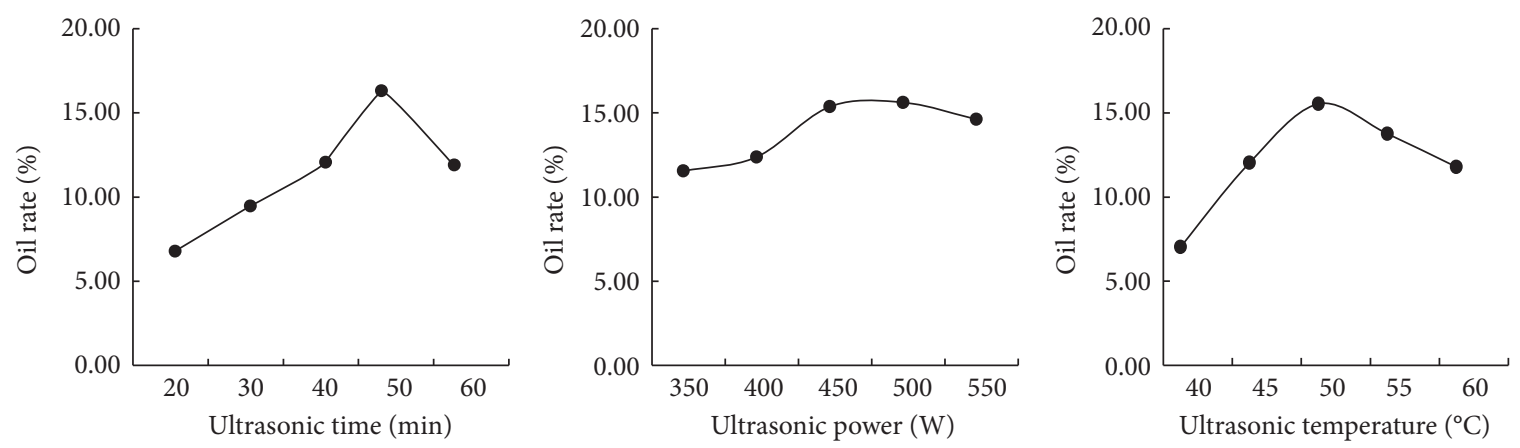

FIGURE 2: Influence of different factors on the yield of palm seed oil by ultrasound-assisted flash extraction.

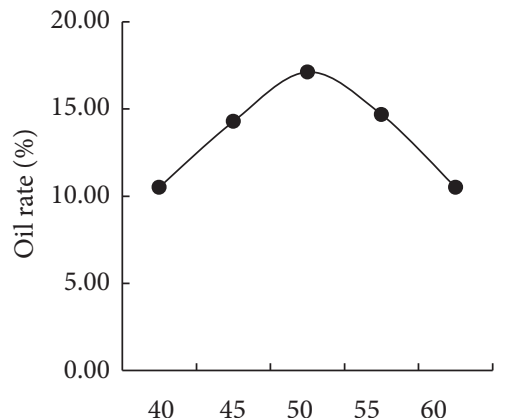

Extraction temperature $\left({ }^{\circ} \mathrm{C}\right)$
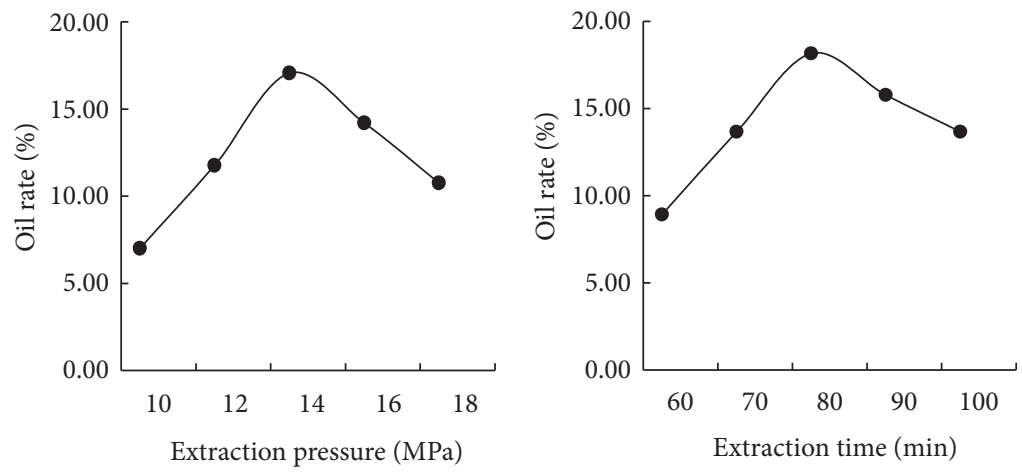

Figure 3: Influence of different factors on oil yield of palm seed by supercritical extraction.
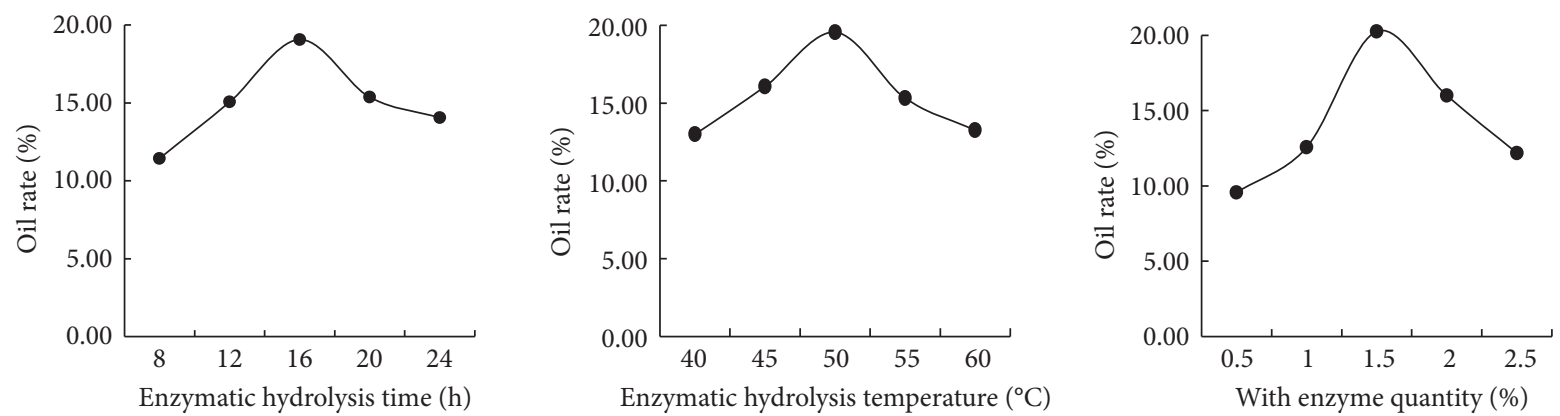

FIGURE 4: Influence of different factors on oil yield of palm seed by hydroenzymatic extraction.

namely, ultrasonic temperature $45^{\circ} \mathrm{C}$, ultrasonic power $450 \mathrm{~V}$, and ultrasonic time $50 \mathrm{~min}$ [17].

\subsubsection{Orthogonal Experiment of Supercritical Extraction of} Palm Seed Oil. The orthogonal experiment of supercritical extraction of palm seed oil and the factor levels are shown in Table 5, and the orthogonal experiment is shown in Table 6.

It can be seen from Table 6 that, under the supercritical extraction experiment of palm seed oil, the extraction temperature, extraction time, and extraction pressure all had influences on the extraction rate of palm seed oil. Because of $\mathrm{B}>\mathrm{C}>\mathrm{A}$, the extraction pressure was greater than the extraction time was greater than the extraction temperature, among which the extraction pressure had the greatest influence. The optimal extraction conditions were as follows: $\mathrm{A}_{2} \mathrm{~B}_{2} \mathrm{C}_{2}$, extraction pressure $20 \mathrm{MPa}$, extraction temperature $50^{\circ} \mathrm{C}$, and extraction time $60 \mathrm{~min}$ [18].

4.2.4. Orthogonal Experiment of Oil and Water Extraction of Palm Seed. The orthogonal experiment of water enzymatic extraction of palm seed oil and the factor levels are shown in Table 7, and the orthogonal experiment is shown in Table 8.

It can be seen from Table 8 that, in the water enzymatic extraction experiment of palm seed oil, the enzymatic hydrolysis time, the enzymatic hydrolysis temperature, and the amount of enzymes added all have influences on the oil yield obtained. Because of $\mathrm{B}>\mathrm{A}>\mathrm{C}$, it can be seen that the enzymatic hydrolysis temperature is greater than the amount 
TABLE 1: Factor levels of the flash extraction method.

\begin{tabular}{lccc}
\hline Horizontal solid-liquid & Ratio of $1: 10$ & Extraction time (s) & Extraction voltage (v) \\
\hline 1 & 1 & 60 & 100 \\
2 & 2 & 90 & 150 \\
3 & 3 & 120 & 200 \\
\hline
\end{tabular}

TABLE 2: Orthogonal experimental design and results of oil flash extraction from palm seed.

\begin{tabular}{lcccc}
\hline No. & A & B & C & Oil yield (\%) \\
\hline 1 & 1 & 1 & 1 & 11.48 \\
2 & 1 & 2 & 2 & 15.65 \\
3 & 1 & 3 & 3 & 20.86 \\
4 & 2 & 1 & 2 & 13.58 \\
5 & 2 & 2 & 3 & 16.24 \\
6 & 2 & 3 & 1 & 17.45 \\
7 & 3 & 1 & 3 & 15.85 \\
8 & 3 & 2 & 1 & 16.26 \\
9 & 3 & 3 & 2 & 16.44 \\
$\mathrm{~K}_{1}$ & 47.99 & 40.91 & 45.19 & \\
$\mathrm{~K}_{2}$ & 47.27 & 48.15 & 45.67 & \\
$\mathrm{~K}_{3}$ & 48.55 & 54.75 & 52.95 & \\
$\mathrm{R}$ & 1.28 & 13.84 & 2.76 & \\
\hline
\end{tabular}

TABLE 3: Factor levels of the ultrasound-assisted extraction method.

\begin{tabular}{lccc}
\hline Horizontal ultrasonic & Ultrasonic time $(\mathrm{min})$ & Temperature $\left({ }^{\circ} \mathrm{C}\right)$ & Ultrasonic power $(\mathrm{V})$ \\
\hline 1 & 40 & 45 & 400 \\
2 & 50 & 50 & 450 \\
3 & 60 & 55 & 500 \\
\hline
\end{tabular}

TABLE 4: Orthogonal experimental design and results of ultrasonicassisted extraction of palm seed oil.

\begin{tabular}{lcccc}
\hline No. & A & B & C & Oil yield (\%) \\
\hline 1 & 1 & 1 & 1 & 13.38 \\
2 & 1 & 2 & 2 & 18.00 \\
3 & 1 & 3 & 3 & 14.50 \\
4 & 2 & 1 & 2 & 15.25 \\
5 & 2 & 2 & 3 & 15.20 \\
6 & 2 & 3 & 1 & 13.25 \\
7 & 3 & 1 & 3 & 14.55 \\
8 & 3 & 2 & 1 & 13.08 \\
9 & 3 & 3 & 2 & 14.85 \\
$\mathrm{~K}_{1}$ & 43.88 & 43.18 & 39.71 & \\
$\mathrm{~K}_{2}$ & 45.78 & 48.05 & 48.10 & \\
$\mathrm{~K}_{3}$ & 42.38 & 42.60 & 44.25 & \\
$\mathrm{R}$ & 3.40 & 5.45 & 8.39 & \\
\hline
\end{tabular}

of enzymes added, among which the enzymatic hydrolysis temperature has the greatest influence. The optimal extraction conditions of palm seed oil were as follows: $\mathrm{A}_{2} \mathrm{~B}_{2} \mathrm{C}_{1}$, enzymatic hydrolysis time $16 \mathrm{~h}$, enzymatic hydrolysis temperature $50^{\circ} \mathrm{C}$, and enzymatic content $2.0 \%$ [19].

4.3. Verification Experiment. The experimental verification results of the optimal combination of the above four palm seed oil extraction methods are shown in Table 9.
As can be seen from Table 9, among the four extraction methods of palm seed oil, the oil yield of aqueous enzymeassisted extraction was the highest, and the best extraction method of palm seed oil was selected after comprehensive consideration [20].

4.4. Comparison of Extraction Rates of Oil from Different Varieties of Palm Seeds. The oil yield of oil extracted from 4 different varieties of palm seeds was compared and analyzed by enzymatic hydrolysis. The results are shown in Table 10.

As can be seen from Table 10, among the four palm varieties, under the same water enzymatic extraction conditions and the same technology, the palm fan with the highest seed oil yield was considered to be the most suitable variety for oil extraction of palm fan [21].

\subsection{Physical and Chemical Indexes of Palm Seed Grease.} Under the optimal extraction conditions, the oil of palm seed was extracted by enzymatic method and its physical and chemical indexes were determined. The results are shown in Table 11 .

As can be seen from Table 11, palm seed oleic acid value, $\mathrm{KOH}$ of $3.28 \mathrm{mg} / \mathrm{g}$ is relatively low, and free fatty acid content is relatively low. The peroxide value of $7.3 \mathrm{mmol} / \mathrm{kg}$ was higher, which was easy to oxidize and deteriorate. The 
TABLE 5: Factor levels of supercritical extraction method.

\begin{tabular}{lccc}
\hline Horizontal & Extraction temperature $\left({ }^{\circ} \mathrm{C}\right)$ & Extraction pressure $(\mathrm{MPa})$ & Extraction time $(\mathrm{min})$ \\
\hline 1 & 45 & 15 & 30 \\
2 & 50 & 20 & 60 \\
3 & 55 & 25 & 90 \\
\hline
\end{tabular}

TABLE 6: Orthogonal design and results of supercritical extraction of palm seed oil.

\begin{tabular}{lcccc}
\hline No. & A & B & C & Oil yield (\%) \\
\hline 1 & 1 & 1 & 1 & 12.25 \\
2 & 1 & 2 & 2 & 18.30 \\
3 & 1 & 3 & 2 & 14.55 \\
4 & 2 & 1 & 3 & 17.25 \\
5 & 2 & 2 & 1 & 17.85 \\
6 & 2 & 3 & 3 & 14.58 \\
7 & 3 & 1 & 1 & 13.80 \\
8 & 3 & 2 & 2 & 14.45 \\
9 & 3 & 3 & 43.58 & \\
$\mathrm{~K}_{1}$ & 46.10 & 44.30 & 50.03 & \\
$\mathrm{~K}_{2}$ & 49.68 & 51.90 & 46.20 & \\
$\mathrm{~K}_{3}$ & 44.03 & 43.61 & 6.45 & \\
$\mathrm{R}$ & 5.65 & 8.29 & & 2 \\
\hline
\end{tabular}

TABLE 7: Factor levels of the water enzymatic extraction method.

\begin{tabular}{lccc}
\hline Horizontal & Enzymatic hydrolysis temperature $(\mathrm{h})$ & With enzyme quantity $(\%)$ & Enzymatic hydrolysis $\left({ }^{\circ} \mathrm{C}\right)$ \\
\hline 1 & 8 & 1 & 50 \\
2 & 16 & 2 & 55 \\
3 & 24 & 3 & 60 \\
\hline
\end{tabular}

TABLE 8: Orthogonal experimental design and results of supercritical extraction of palm seed oil.

\begin{tabular}{lcccc}
\hline No. & A & B & C & Oil yield (\%) \\
\hline 1 & 1 & 1 & 1 & 17.55 \\
2 & 1 & 2 & 2 & 15.28 \\
3 & 1 & 3 & 3 & 14.82 \\
4 & 2 & 1 & 2 & 16.56 \\
5 & 2 & 2 & 3 & 15.74 \\
6 & 2 & 3 & 1 & 17.68 \\
7 & 3 & 1 & 3 & 13.92 \\
8 & 3 & 2 & 1 & 16.08 \\
9 & 3 & 3 & 2 & \\
$\mathrm{~K}_{1}$ & 47.65 & 44.94 & 48.15 & \\
$\mathrm{~K}_{2}$ & 48.98 & 51.39 & 47.92 & \\
$\mathrm{~K}_{3}$ & 47.26 & 47.58 & 47.82 & \\
$\mathrm{R}$ & 1.72 & 6.43 & 0.33 & \\
\hline
\end{tabular}

TABLE 9: Comparison of the best results of 4 extraction methods of palm seed oil.

\begin{tabular}{lc}
\hline Extraction method & Oil yield (\%) \\
\hline Flash extraction & 10.26 \\
Ultrasonic assisted extraction & 15.28 \\
Supercritical extraction & 14.16 \\
Water enzymatic assisted extraction & 16.29 \\
\hline
\end{tabular}

saponification value, $\mathrm{KOH}$ of $197 \mathrm{mg} / \mathrm{g}$, is basically in line with the requirement of saponification value of edible oil [22].

4.6. Fatty Acid Composition of Palm Seed Oil. Commodity oil was used as reference GB/T17376-2008 for sample pretreatment, and GC-MS was used for determination and 
TABLE 10: Comparison of oil yield results of different varieties of palm seed under optimal technological conditions.

\begin{tabular}{lc}
\hline Varieties & Oil yield (\%) \\
\hline Spell brown & 11.44 \\
Mountain brown & 10.22 \\
Fan palm & 16.37 \\
Dickinson brown & 10.58 \\
\hline
\end{tabular}

TABle 11: Physical and chemical properties of palm seed oil.

\begin{tabular}{lc}
\hline Project & Indicators \\
\hline Acid value $(\mathrm{KOH}) /(\mathrm{mg} / \mathrm{g})$ & 3.22 \\
Peroxide value $(\mathrm{mmol} / \mathrm{kg})$ & 7.3 \\
Saponification value $(\mathrm{KOH}) /(\mathrm{mg} / \mathrm{g})$ & 197 \\
Iodine value $(\mathrm{I}) /(\mathrm{g} / 100 \mathrm{~g})$ & 126 \\
Nonsaponification material $(\%)$ & 1.37 \\
Transparency $\left(20^{\circ} \mathrm{C}, 24 \mathrm{~h}\right)$ & Clear \\
Smell & Light yellow oily
\end{tabular}

TABLE 12: Fatty acid composition and content (\%) of palm seed oil.

\begin{tabular}{lcc}
\hline Fatty acids & Palm seed oil & Product oil \\
\hline Palmitic acid $(\mathrm{C} 16: 0)$ & 8.09 & 6.66 \\
Nutmeg acid $(\mathrm{C} 14: 0)$ & 0.55 & 0.47 \\
Stearic acid $(\mathrm{C} 18: 0)$ & 3.66 & 3.27 \\
Oleic acid $(\mathrm{C} 18: 1)$ & 18.45 & 21.17 \\
Linolenic acid $(\mathrm{C} 18: 3)$ & 24.22 & 25.36 \\
Linoleic acid $(\mathrm{C} 18: 2)$ & 42.36 & 43.29 \\
Peanut acid $(\mathrm{C} 20: 0)$ & 0.78 & 0.64 \\
Arachidonic acid $(\mathrm{C} 20: 1)$ & 0.48 & 0.34 \\
Oleic acid & 0.26 & 0.17 \\
\hline
\end{tabular}

analysis according to Sun Hong's method. The results are shown in Table 12.

It can be seen from Table 12 that the fatty acid composition of palm seed oil is similar to that of olive oil, and the palm seed oil contains relatively low saturated fatty acid accounting for about $13.84 \%$. They were mainly palmitic acid and stearic acid. The contents of unsaturated fatty acids were $83.23 \%$, mainly linoleic acid, linolenic acid, and oleic acid [23].

\section{Conclusions}

In this experiment, the extraction rate of palm seed oil was taken as the index, and the orthogonal experiment was used to optimize the extraction conditions of different extraction methods [24].

The water enzyme method was the best extraction method of palm seed oil. The single-factor conditions of extraction were as follows: the amount of enzyme added, the time of enzymolysis, and the temperature of enzymolysis. Under these conditions, the extraction rate of palm seed oil was $16.55 \%$. The extraction rate of oil from four different varieties of palm seeds was compared by water enzyme method. It was determined that palmetto microphylla seed was the most suitable extraction material for palm seed oil. The oil of palm seed mainly contains linoleic acid, oleic acid, linolenic acid, and stearic acid by GC-MS analysis. Highly unsaturated fatty acid, basically close to the standard of edible oil, is a good health edible oil. It provides a reference for the development of blend oil with health care function according to proper proportion of edible oil and palm seed oil.

\section{Data Availability}

The data used to support the findings of this study are included within the article.

\section{Conflicts of Interest}

The authors of this paper declare that they have no conflicts of interest regarding the publication of this paper.

\section{Authors' Contributions}

All authors have equally contributed to this paper.

\section{Acknowledgments}

This study was supported by the Educational Commission of Anhui province of China, under Grant no. KJ2017A627, and Quality Engineering Project of Anhui Province, under Grant nos. 2016sxzx021 and 2020sxzx12.

\section{References}

[1] J. Mcnutt and Q. He, "Development of biolubricants from vegetable oils via chemical modification," Industrial \& Engineering Chemistry, vol. 6, no. 12, pp. 36-39, 2016.

[2] A. Carbonell-Verdu, L. Bernardi, D. G. Garcia, L. SanchezNacher, and R. Balart, "Development of environmentally friendly composite matrices from epoxidized cottonseed oil," European Polymer Journal, vol. 1, no. 15, pp. 63-68, 2015.

[3] Y. F. Xiang, R. J. Liu, M. Chang, Q. Z. Jin, and X. G. Wang, "Preparation and characteristics of sea-buckthorn seed oil microcapsule," China Oils and Fats, vol. 45, no. 1, pp. 12-16, 2020.

[4] L. L. Dai, L. L. Fan, Y. H. Liu et al., "Production of bio-oil and biochar from soapstock via microwave-assisted cocatalytic fast pyrolysis," Bioresource Technology, vol. 8, pp. 225-129, 2017.

[5] Y. Xia, H. Zang, and J. Y. Xiao, "Effects of oil extraction processes on polyphenols and antioxidant activity of grape seed oil," China Oils and Fats, vol. 43, no. 6, pp. 1-6, 2018.

[6] W. Gao, Y. Wang, W. Wang, and L. Shi, "The first multiplication atom-bond connectivity index of molecular structures in drugs," Saudi Pharmaceutical Journal, vol. 25, no. 4, pp. 533-541, 2015.

[7] J. B. Liu, S. Akram, M. Javaid, A. Raheem, and R. Hasni, "Bounds of degree-based molecular descriptors for generalized F -sum graphs," Discrete Dynamics in Nature and Society, vol. 2021, pp. 1-17, Article ID 8821020, 2021.

[8] J. B. Liu, M. Arockiaraj, M. Arulperumjothi, and S. Prabhu, "Distance based and bond additive topological indices of certain repurposed antiviral drug compounds tested for treating COVID -19," International Journal of Quantum Chemistry, vol. 121, no. 10, p. e26617, 2021. 
[9] N. Dehgardi and J.-B. Liu, "Lanzhou index of trees with fixed maximum degree," MATCH Communications in Mathematical and in Computer Chemistry, vol. 86, pp. 3-10, 2021.

[10] J.-B. Liu, X.-F. Pan, F.-T. Hu, and F.-F. Hu, "Asymptotic Laplacian-energy-like invariant of lattices," Applied Mathematics and Computation, vol. 253, pp. 205-214, 2015.

[11] C. Liu, "A note on domination number in maximal outerplanar graphs," Discrete Applied Mathematics, vol. 293, pp. 90-94, 2021.

[12] W. Fang, Z.-Q. Cai, and X.-X. Li, "Minimum detour index of tricyclic graphs," Journal of Chemistry, vol. 2019, pp. 1-8, Article ID 6031568, 2019.

[13] M. Imran, M. Siddiqui, A. Abunamous, D. Adi, S. Rafique, and A. Baig, "Eccentricity based topological indices of an oxide network," Mathematics, vol. 6, no. 7, p. 126, 2018.

[14] I. Gutman, "Multiplicative Zagreb indices of trees," Bulletin of Society of Mathematicians Banja Luka, vol. 18, no. 7, pp. 17-23, 2011.

[15] J. K. An, Y. L. Liu, and H. L. Liu, "The relationship between total polar components and polycyclic aromatic hydrocarbons in fried edible oil," Food Additives \& Contaminants: Part A, vol. 9, no. 34, pp. 1596-1608, 2017.

[16] F. Anjum, F. Anwar, A. Jamil, and M. Iqbal, "Microwave roasting effects on the physico -chemical composition and oxidative stability of sunflower seed oil," Journal of the American Oil Chemists' Society, vol. 9, no. 14, pp. 777-782, 2016.

[17] C. Delorme, O. Favaron, and D. Rautenbach, "On the randic index,” Discrete Mathematics, vol. 257, no. 1, pp. 29-38, 2012.

[18] Z.-Q. Cai, A. Rauf, M. Ishtiaq, and M. K. Siddiqui, "On vedegree and ev-degree based topological properties of silicon carbide si2c3-ii[p, q]," Polycyclic Aromatic Compounds, vol. 4, pp. 1-15, 2020.

[19] J.-B. Liu, Q. Zheng, Z.-Q. Cai, and S. Hayat, "On the laplacians and normalized laplacians for graph transformation with respect to the dicyclobutadieno derivative of [n]Phenylenes," Polycyclic Aromatic Compounds, vol. 7, pp. 1-22, 2020.

[20] L. Xiao, C. Li, D. Chai et al., "Volatile compound profiling from soybean oil in the heating process," Food Science \& Nutrition, vol. 8, no. 2, pp. 1139-1149, 2020.

[21] X. H. Pang, "Comparison of oxidative stability of sacha inchi oil,linseed oil and perilla seed oil," China Oils and Fats, vol. 46, no. 1, pp. 32-37, 2021.

[22] H. Zhang and G. Mittal, "Biodegradable protein-based films from plant resources: a review," Environmental Progress \& Sustainable Energy, vol. 29, no. 2, pp. 203-220, 2010.

[23] H. Wiener, "Structural determination of paraffin boiling points," Journal of the American Chemical Society, vol. 69, no. 1, pp. 17-20, 1947.

[24] M. Hu, B. K. Qi, and Y. F. Sun, "Composition and related properties of soybean emulsion," China Oils and Fats, vol. 44, no. 1, pp. 45-52, 2019. 